who monitors the care plan and to whom the patient and relatives can turn. These principles of care are appropriate for mildly depressed patients seeing one doctor in an outpatient clinic as well as for a patient with severe schizophrenia who sees several professionals.

I believe that the current frustrations with the care programme approach have arisen largely because it has highlighted the fact that, in many areas, good practice is impossible to implement owing to insufficient resources. All too often mental health services offer little more than reactive, crisis driven care, with their high staff turnover making continuity of care an impossible aspiration. The care programme approach is helping to show the true picture of mental health services, and it is not a pretty picture.

Marshall points out that a recent controlled trial reported a doubling of admissions to hospital after the introduction of the care programme approach. ${ }^{2}$ Rather than being interpreted as a failure of the approach, this may indicate that the approach is doing its job-that is, helping services maintain contact with patients and drawing attention to unmet need, including the need for admission to hospital. It is oversimplistic to regard admission to hospital as a measure of failure.

It is easy to criticise the care programme approach, but can anyone suggest a better way of developing proactive and comprehensive mental health services into the next century?

\section{MICHAEL PHELAN}

Department of Psychiatry,

Charing Cross Hospital,

London W6 8RU

1 Marshall $M$. Case management: a dubious practice. $B M \mathcal{Y}$ 1996;312:523-4. (2 March.)

2 Tyrer P, Morgan J, van Horn E, Jayakody M, Evans $K$ Brummell $\mathrm{R}$, et al. A randomised controlled study of close monitoring of vulnerable psychiatric patients. Lancet 1995;345:756-9.

\section{Case management confers substantial}

\section{benefits}

EDITOR,-Max Marshall claims that case management is "a dubious practice...underevaluated and ineffective....bedevilled by a tendency to lump two different approaches under one name." $\mathrm{He}$ then bedevils it further by equating care programming with "standard" case management, and what is frequently referred to in the American literature as case management as "assertive community treatment." In a recent editorial on the subject in the Lancet "case" and "care" were used interchangeably. ${ }^{2}$

These terms are not difficult to distinguish, and much is to be achieved by distinguishing them. The meaning of case management evolved rapidly, reflecting the context in which it operated and increasing understanding of its working. Initially the focus was on the coordination of care and obtaining access to support and benefits by an office based administrator, who often had no health or social services background. This model ("brokerage case management") was soon recognised to be of limited value in serious mental illness, and this was confirmed by controlled studies. ${ }^{3}$ Case managers shifted their emphasis to more direct care ("full support" or "clinical case management"), which has become the dominant approach in the United States.

Clinical case management increasingly emphasises outreach, small caseloads, and a broad clinical remit. Consequently, the term is now virtually synonymous with what is done by the assertive community treatment team (itself a concept that evolved from "training in community living"). These teams have been subjected to over 13 randomised controlled trials, which have overwhelmingly shown their value. ${ }^{4}$

The research evidence is therefore clear and unusually abundant. Brokerage case management (renamed care management in British social services) is costly, with no added benefits for patients, ${ }^{35}$ and its adoption as policy in England threatens to damage mental health social work severely. ${ }^{2}$ Case management (clinical case management) has been extensively researched and confers substantial benefits.

Use of the care programme approach with long term and complex problems arises logically from the philosophy of case management, is clinically coherent, and generates little controversy. Insistence that every patient of the menta health services should be included in this approach is a bureaucratic diktat that perpetuates confusion over whether it is clinically derived practice or an administrative procedure.

All three processes have a clear clinical identity. For two of them adequate evidence exists to make informed decisions about their value. For the care programme approach clinicians need to take responsibility for shaping and researching it. Administratively coherent but clinically nonsensical definitions should not be allowed to confuse thinking or determine practice.

St George's Hospital Medical School,

Department of Mental Health Sciences,

London SW 17 ORE

1 Marshall M. Case management: a dubious practice. BMY 1996;312:523-4. (2 March.)

2 Care-management: a disastrous mistake [editorial]. Lance 1996;345:399-401.

3 Franklin JL, Solovik B, Mason M, Clemons JR, Miller GE. An evaluation of case management. Am $\mathcal{f}$ Public Health 1994;77:674-8.

4 Solomon P. The efficacy of case management services for severely mentally disabled clients. Community Ment Health $\mathscr{f}$ 1992;28:163-80.

5 Marshall M, Lockwood A, Gath D. Social services case-management for long-term mental disorders: randomised controlled trial. Lancet 1995;345:409-12.

\section{Administrative demands of care} programme approach

EDITOR,-Max Marshall makes the point that the care programme approach has never been fully evaluated, and that its American counterpart, case management, has not proved to be a particularly successful approach. ${ }^{1}$ In Britain, some studies have claimed that the approach is successful-for example, in tailoring care to individual needs-whereas others have shown that care programme approach fails to improve outcome and has no effect on rates of suicide or reoffending. ${ }^{2} 3$

We investigated the implementation of this approach within a mental health trust, studying administrative demands and the opinions of practitioners regarding the potential benefits and problems. Our results suggest that the care programme approach increases workload disproportionately to its perceived benefits. The most commonly cited problems included increased demands of time and workload due to extra administrative tasks and, perhaps more worryingly, the consequent detraction from time available to spend with patients.

The same issues were highlighted in the observational component of the study, using a multidisciplinary team meeting. These meetings are now required to discuss and review the care plans and complete the associated paperwork for all clients, but data from one such meeting indicates that this may not actually be feasible or appropriate in terms of time and human resources. In the one meeting studied, $110 \mathrm{~min}$ utes were spent discussing matters generated solely by the care programme approach Fourteen practitioners were present, so this amounted to a total of 1540 minutes (25.7 hours) of extra staff time. Previously the average meeting time was 60 minutes; this meeting was 170 minutes long. Practitioners had accommodated this added time commitment by cancelling ward rounds and community visits. Therefore, 25.7 hours of time had been effectively taken away from patients. During this time, only 13 patients were discussed.

In a trust currently dealing with over 7000 open cases, our preliminary results. suggest that the demands the care programme approach puts on the system are logistically impractical, if not impossible.

It seems ironic that, in the current climate of evidence based medicine, the care programme approach continues to be not only advocated but enforced, despite a lack of supporting evidence for its usefulness. It would seem that this approach is being pursued so relentlessly because of its status as a government policy, rather than on its own merit.

CLAIRE EASTON Research officer FEMI OYEBODE Consultant psychiatrist

Research and Development Unit,

Queen Elizabeth Psychiatric Hospital,

Edgbaston,

Birmingham B15 2QZ

Marshall $M$. Case management: a dubious practice. $B M \mathcal{F}$ 1996;312:523-4. (2 March.)

2 Shepherd G, King C, Tilbury J, Fowler D. Implementing the care programme approach. Fournal of Mental Health 1995; 4:261-74.

3 Pierides M, Craig T, Roy D. The CPA in West Lambeth: 3 year results. Proceedings of the winter meeting of the Royal College of Psychiatrists, 1996. London: Royal College of Psychiatrists, 1996.

\section{Continuing transmission of sexually transmitted diseases among patients infected with HIV}

\section{Qualitative study gave different results}

EDITOR,-M A Catchpole and colleagues report evidence of continued transmission of sexually transmitted diseases in homosexual and bisexual men infected with HIV-1. ${ }^{1}$ They reach several conclusions based on these findings, including that $(a)$ unsafe sexual practices are continuing in substantial numbers of such men; (b) only a minority of these cases of sexually transmitted diseases are likely to be due to long term infections, infections acquired during safer sexual practices, or infections acquired in relationships in which the partners are aware of their infectious status; and $(c)$ changes in sexual behaviour after the diagnosis of HIV infection are short lived or infrequent.

We recently completed a qualitative study of the sexual health of HIV positive homosexual and bisexual men; the results shed further light on the debate concerning the sexual practices of this group of patients. The study sample $(n=40)$ was recruited through community groups $(n=25)$ and HIV outpatient clinics $(n=15)$ covered by the Northern and Yorkshire Health Authority. All the men in our study reported regularly practising safer sex with casual partners and partners whose status was unknown or negative. Only three men reported isolated incidents of unsafe sex with casual partners or those of unknown serostatus after their own HIV infection was diagnosed. All other reports of unsafe sex $(n=8)$ occurred within regular relationships where the partner was also positive. Our participants typically reported that they 